\title{
Effectiveness of using the iPad in Learning to Acquire the Mental and Performance Skills in Teaching Social Studies Curriculum
}

\author{
Maadi Mahdi Alajmi ${ }^{1, *} \&$ Hanan Abdullah Al-Hadiah ${ }^{2}$ \\ ${ }^{1}$ The College of Education, Kuwait University, State of Kuwait \\ ${ }^{2}$ Ministry of Education, Kuwait \\ *Correspondence: The College of Education, Kuwait University, State of Kuwait. E-mail: drmaadi1@gmail.com
}

Received: December 26, 2016

Accepted: January 12, 2017 Online Published: February 5, 2017

doi:10.5430/jct.v6n1p1

URL: http://dx.doi.org/10.5430/jct.v6n1p1

\begin{abstract}
This study aims to examine the effectiveness of using the iPad in learning to acquire the mental and performance skills in teaching the social studies. Using experimental design method, the study compared two groups: (a) experimental, taught using the $\mathrm{iPad}$, and (b) control group, taught using the traditional learning without iPad. A total of 48 (24experimental group and 24 control group) eighth grade students in state of Kuwait participated in this study. The study started on the second semester on 2015-2016 on the average of 6 weeks. After the test on the study sample and the statistical processing, the results revolved that: (1) there are no significant differences between the experimental and the control group in mental performance in pre-test score. (2) There are no significant differences between the experimental and the control group in skills performance in pre-test score. (3) There are significant differences between the experimental and the control group in mental performance in post-test score in favor of experimental group. (4) There are significant differences between the experimental and the control group in skills performance in post-test score in favor of experimental group. Based on the results, the study concluded with relevant recommendations regarding the implementation of using iPad technology in education, and suggested some further studies in this topic.
\end{abstract}

Keywords: iPad; mobile learning; mental performance; performance skills

\section{Introduction}

The Field of Education witnesses the enormous cognitive development in the generation of knowledge, ideas and information. Those who interested in the education have many of the requirements to accommodate this development within educational institutions to achieve the optimal learning for the learners, which is necessary for teachers to follow the modern techniques and means within the classroom to meet with the global educational development. Whereas Al-Kubaisi and Al-Farhan (2012)points to use the modern techniques in the learning was no longer an optional order which education institutions resort to, but it becomes fundamental condition for the possibility of its survival.

Saleem (2012) identifies the educational technology as it is an organized process to plan, implement and evaluate the difference aspects of the educational process according to clear and definite general and special goals and employs a group of the human elements and various education resources with a view of access to better education. The role of the educational technology is concentrated in the necessity to employ the learner for what he learned in his life outside the school boundaries.

This is corresponding to the modern educational theory which considers that the goal of the educations is not only to keep the information but moved even further as to interaction, participation and cooperation. The more the degrees of the interaction and harmony between the elements of the learning system increased, the learning opportunities increased (Mahdy, 2015). Thus, educational technology includes all means and modern devices such as computers and mobile devices which iPad Device is one of its forms and it can be used within the educational institutions and in the learning process. 


\subsection{Education Technology and Teaching the Social Studies}

Social Studies Subject is one of the education materials to be taught within the education institution and it needs the usage of technology in its teaching to use it in analysis and study the geographical phenomena (Natural and Human), collecting data from the several resources to study of the human history on this earth, as well as the benefits of its usage in teaching and learning Geography as mentioned by (Abd El Basset, 2005) which is as follows:

1. Educational Vitality: As the technology provides to the students interactive learning environment to encourage them on integration into the educational process through conversion the read material to live scenes through the images and movies.

2. Increasing the Student Achievement: Through supporting the process of learning the geographical subjects, students are learning better when using the audible and visual resources.

3. Development the High Levels in the Thinking Skills: There are some software specially designed to develop the student skills in collecting the geographical information, organizing, analyzing and using it in problem solving.

4. Motivation: Education Technology contributes in making the process of learning the geography an impressive process for students and teachers together.

5. Development the Skill of the Cooperation and Working in a Group: As the Modern Styles for Information Technology are essential tool in providing a fertile environment to cooperate between the students and teachers and between the students themselves, as it provides various resources to collect the geographical information and preset and exchange it between them which is reflected positively on student learning.

Given these benefits, Farsi Study (Farsi, 2016) recommended teachers of the social studies to use two types of technological devices appropriate for the development of the student skills and complying with the structural view for the Education. First: Public Techniques: It can be used to achieve the general goals for the social studies which can be used to activate the student's role in the educational process and it doesn't need special skills to use it.

This type includes the E-mail, Smart Board, Digital Files, YouTube Program and Electronic Student Discussions Programs.Second Type: Special Techniques: It can be used to achieve the special goals for the Academic Subject. It consists of the program which contains useful applications for both students and teachers of the social studies. It needs special skills to use it in the Education, Conferences, Digital Games and Digital Learning Pages. These technological devices have new vision for the learning and the most important innovations in the Educational Process. In the Recent Years, a new type of the technological learning emerged which is Mobile Learning.

\subsection{The Essence of the Mobile Learning}

Several Forms of Learning have recently emerged due to the spread of the electronic knowledge among students in all phases of education. As general and special Wireless Communications have been invested (Al-Hamami, 2006). The concept of the mobile learning and learning via mobile devices emerged, each of Qureshi, Padowd, Abdelal, Abdelatti and Al-Hafnawi (2015) identifies the mobile learning as the usage of the Electronic Instruments portable and movable such as Personal Digital Assistants(PDAs), Mobile Phones and Tablet Personal Computers in the Education.

\subsection{Types of Communication Mobile Devices}

Al-Omari (2012) mentions several types of Learning Mobile Devices which can be used in the educational process to take advantage of its several features which are as follows:

1. Mobile Phones: Mobile or Cellular Phones are means of communications which depends on wireless communication and it can be portable within a certain area covered with Wireless Broadcasting Network.

2. Tablet Personal Computers: It is type of computers, which its size is equal to the size of the palm approximately. It can be portable and used in storing and reviewing the text data and multimedia. It can be used as Desktop Computer with all of its applications.

3. Laptop: It is type of Computers, which its size is slightly larger than the Tablet Personal Computer and it has nearly the same features, but its storage capacity may be greater than the Tablet Personal Computer.

4. Personal Digital Assistants (PDAs): They are portable computer devices which are used to store and organize the data, to organize the personal appointments, to prepare lists of the personal tasks, to write notices, to be able to run text format programs, calculation tables, games and reading the E-Books, to communicate the world wide web and to send and review the emails. 
This development has led to learners rush on acquisition the mobile devices and dealing with them in some way due to its features which distinguished it from the other technological devices as mentioned by Al-Rwaily (2014): such as light weight and easy portability; Providing a lot of Educational Applications and the speed of its downloading through the Application Store which contains more than 65000 education application; access to the information sources, E-books, Images, Maps and others easily and quickly and the possibility of using these devices as educational and personal tool for the learner in anytime and anywhere as it combines the features of the mobile phone and computer.

\section{4 iPad Device in Education}

iPad Device is one of the modern techniques internationally deployed and considers one of the mobile learning forms. Whereas (Irelan\&Woollerton, 2010) identifies it as tablet computer device including touch screen to allow users to control the device using fingers. Al-Rwaily (2014) adds that the iPad Device is working by IOS System and running several types of multimedia such as newspapers, magazines, digital books, video, music, games and all iPhone Programs.

In 2010, iPad Device appeared as invocations of era which stunned the world, so its usage has been activated in several fields, as (Huber 2012) points that the device was designed to be a source of the books and movies and operator for applications, music and Internet. (Irelan\& Woollerton, 2010) has mentioned that the iPad Device has a role in providing some of the facilities in the educational process, as students can be able to choose the audible and visual materials to commensurate their needs, uploading and sharing information with others, using it as a device to present the information and presentations due to its containing easy to use applications.

\subsection{Reasons of using IPad Device in the Education Field}

Du'mus (2011) points to that there are several reasons require that using of the modern techniques represented in iPad Device and Computers in the Education which are as follows:

1. Knowledge Explosion: Our world today is full of several discoveries in various walks of life and expansion of the knowledge size as well as introduction of new classifications of knowledge requiring its followings and using in the Education Field.

2. Human Overpopulation: which requires the usage of the technological means to secure the education opportunities and provide the greatest opportunity for the largest number of students.

3. Low Efficiency in the Education Process: The traditional viewpoint for education doesn't encourage the student on creativity due to its reliance on the memorization and indoctrination. In order to increasing the output efficiency of the Education, technology must be employed and forming the sound skills and reliance on the Higher Order Thinking.

4. Motivating of the Learner: The technological means as well as It provides the scientific material with new styles, it makes the student to get rid of the Negativity, as it encourages the students on participation and activity with making the opportunity available for them to express their opinions and walking into the levels of the Education.

Despite the need to use the technical means to face the educational problems, but there are obstacles standing in front of its application in the Education Field. Al-Qulla and Siyam(2011) summarizes it in the inability of the teacher to get rid of the usage of the verbal method in the teaching, far from the duplicated traditional way, insufficiency of the hours dedicated to study the educational techniques material in the institutions of preparation the teacher and his training on using the devices and advanced tools, clear deficiency in preparations of the school buildings as the entry of any new technique in the class requires amendment in the class environment and components, non-allocation of appropriate budget to produce the technological educational means; increasing in the classroom density of students, multiplicity of the teacher's responsibilities represented in the teaching hours beside the multiplicity of administrative and additional business and the lack of material and moral incentives which are allocated to foster the innovation and renewal.

iPad Device provides many of the benefits for the students if it has been used within the classroom. Both of (Shepard \& Reeves, 2011) praises that iPad Device surpasses that iPhone Device in the Education as it is characterized by the Big Screen, Light Weight and Ease of downloading the educational applications. (Shepard \& Reeves, 2011) and (Karsenti\&Fievez, 2013:146) agree in the Features of the iPad Device which are the following:

- IPad Device increases the motivation of the students for Education.

- Facilitates the process of information sharing among students within the classroom. 
- Improves the reading and writing skills through the modern devices.

- Increases the communication and cooperation process among students themselves and between them and the teacher.

- Facilitates the learning process for the ordinary students and students with learning disabilities within the classroom and develops their various skills.

- Improves the student's technical efficiency and reduces the efforts of the teachers exerted during the school class.

A case study in the University of Southampton in UK in the Administration Management has shown the evaluation of the staff and student viewpoints around the inclusion of the iPad Device in the education process as a tool for education and learning. iPad Devices have been distributed on the staff and students from the Business Administration classroom in the beginning of the Academic Year. Initial Research Results showed that the reactions were positive, acknowledging the benefits of entry the new technology, using of the results by the students widely in the first week as well as the positivity of the staff in their acceptance to the experiment of the iPad Device in the education through its results from benefits in the study (Eyal, 2005). Technology applications which can be used in the educational field through the iPad Device are multiplied. We review some of them below:

- YouTube Program: Abdul Ati (2015) reminds that YouTube is the largest host in the world for the video files produced on a personal level. Features of using YouTube in the Education Field are represented in easy access to knowledge and scientific lectures and the possibility of transforming the world events and cultures through providing the visual multimedia.

- Internet: It is Global Communication Network enable the students to access to sources of knowledge and information collection they needed in the education process to achieve the optimal learning for them. AlHela (2003) adds that the reasons of using the internet network in the education returns to that internet network is a real world example for the ability to obtain information from across the world; encouragement the collective cooperative learning due to the large number of information available, its speed and ability to provide more than one way in teaching.

- Google Earth Application: It is application uses the satellites via Internet Network to provide 3D aerial images to represent real environment for the Earth from which we can able to investigate the natural phenomena and to determine the locations in the world.

- Keynote Applications: It is a program to create interesting presentations using the colors in addition to the possibility of attachment the educational images and movies and sharing them with others by sending them via internet easily.

- Classroom Timer Application: It is application to manage the time of the summer activities by the teacher by displaying the time on the board and alarming at the end of the time of performing the required activity.

\subsection{Challenges of using iPad Device in the Education Process within the Classroom}

(Karsenti\&Fievez, 2013:146) has pointed to that there are several challenges which may face the process of entry the iPad Device in the classroom learning for teachers and students, which are as follows:

- The biggest challenge for teachers represents in that iPad Device leads to distract the students from listening to the explanation of the teacher as a result of their integration in the device which negatively affects their Academic Performance.

- The Difficulty of writing long texts on iPad Device, in addition to inappropriate of some of the school books for loading them on the Device.

Both of (Culen\& Casparini, 2011: 204) have classified the challenges of using iPad Device in the education through their study around the benefit of using iPad Device in learning and education the active reading. The challenges represented in three divisions which are:

1. Physical Challenges: It represented in the difficulty of recording notes on iPad Device in addition to problems relating to the Internet Network and slowness in the event of the students to use it at the same time.

2. Academic Challenges: They are challenges related to the types of the applications chosen and the extent of its appropriateness to the needs of the students to achieve the better education. 
3. Technological Challenges: It is the most challenges faced by the students and represented in the difficulty of running more than one application at the same time, the process of downloading applications and texts needs long time and lack of supporting iPad Device for the Mobile Memory Function.

\subsection{Disadvantages of using iPad Device in Education}

(Huber, 2012) points to that these disadvantages returns to the users themselves which are:

1. Sometimes students should learn how to use iPad Deviceas they are not share the same prior knowledge.

2. Minority of teachers have experience in the E-learning field or using modern techniques widely.

3. Using the modern techniques in the school may affect the decline of the social communication between teachers and students making the exchange of experiences are harder and leaving some of questions unclear.

We noticed in the field increasing of using the modern techniques in all school subjects, due to its spread significantly between people in general and between students and teachers particularly, as well as ease of its use, interesting design and portability. Each of(Chau, Block \&Jasness, 2014) have pointed to that the advantages of using iPad Device represent in its achieving to cooperation and innovation, effective participation, productivity and digital literacy for students. IPad Device, as a mean of educational technology, falls under the name of the mobile learning. Each of (Rossing, Miller, Cecil \& Stamper 2012) point to that the mobile techniques have several advantages in the education field represented in its availability for the discussion and participation for students within the classrooms, achievement the cooperation and interaction with peers in addition to the acquisition of the knowledge as well as it supports the social structural theory for learning in terms of the ability of the students to learn from others.

\subsection{A Dressing the Problem}

Given the role played by the education technology in improving the learning quality for the student and increasing of its effectiveness (Achtiwa, 2010), it become necessary for us to entry this technology in the education field to achieve the optimal education according to the modern theory for the education which considers the student is the center of the educational process. It becomes necessary for teachers to follow the modern technological means and its using in the educational process. Due to the lack of the Arab Studies around the iPad Device in the Education, this study came to look at the effectiveness of iPad Device in the education. The study problem represents in the following question:

What is the effectiveness of iPad Device in acquisition the mental and performance skills for the students of the preparatory eighth grade in the Social Studies Subject?

The question is branched into four questions:

1. Are there statistically significant differences between the averages of the experimental group and the control group in acquisition of the mental skills in the pre-measurement results?

2. Are there statistically significant differences between the averages of the experimental group and the control group in acquisition of the performance skills in the pre-measurement results?

3. Are there statistically significant differences between the averages of the experimental group and the control group in acquisition of the mental skills in the post-measurement results?

4. Are there statistically significant differences between the averages of the experimental group and the control group in acquisition of the performance skills in the post-measurement results?

\section{Research Focus}

The importance of the study represents in the following:

1- It is consistent with the current trend to the Ministry of Education in Kuwait and their keenness on entry the technology and its usage in order to achieve the benefit for the students.

2- Helping the social studies' Teachers on activating the tablet computer (iPad Device) in teaching.

3- Enabling the students to deal with education technology and giving the pleasure in the learning process.

4- Drawing attention of the school to the importance of providing the equipment needed to activate iPad Device in the classrooms.

5- Guiding those who establish the school curricula to author school books to commensurate with using the applications of iPad Device in the education process. 
The current study aims to recognize the effectiveness of the iPad Device in skills acquisition for the female students, development the mental and performance skills for the female students of the intermediate stage, in addition to encouraging the teachers on using the education technology to achieve better education.

\subsection{Study Tools}

In order to execute this study, the researchers built an achievement test to measure the mental and performance skills for the female students of the intermediate eighth grade in the social studies subject. The educational material represented in the second unit and part of the third unit. In order to applying the experiment, Educational Software has been used prepared by the researcher to be a means to achieve the objective of this study which is:

- Educational Software to teach the mental and performance skills prepared by the researcher:

- Procedures of Preparation the software:

1. Analyzing the theoretical framework to the curriculum of Kuwait and Islamic World to determine the educational activities required to be followed to achieve the learning through iPad in the cooperative learning.

2. Formulation of educational objectives to determine the appropriate applications to achieve the learning through it.

3. Analyzing the mental characteristics of the students which software directed to them in order to the scientific and skilled level for the students needed before the beginning in the learning.

4. Planning the lesson which the program will include in order to distribute the right time to carry out each lesson considering the aesthetic formation of display screens and formulation the content of each lesson to enable the comprehensiveness and accuracy of the display to commensurate with educational position.

5. Determining the appropriate educational applications in the iPad Device represented in Google Earth, Keynote, YouTube application and educational games in addition to take advantage of the multiple possibilities of the device.

6. Determining the activities accompanied by each anticipated educational position in order to provide the opportunity for each individual in the group to play its role in the effective participation through dividing roles between them.

\subsection{Validity and Reliability}

In order to make sure of the validity of the program, the program has been displayed in its initial image on a group of specialists in software from Curriculum Department and teaching methods from Faculty Members in Education Technology, Supervisors and Teachers in Kuwait. Upon their opinions, some amendments have been implemented:

- Including the educational movies in Keynote Application Slides.

- Displaying the objectives of the lesson in the first slide for each presentation.

- Adding the time counter for activities to provoke the activity of female students to raise the speed and level of performance.

The researchers built a test to measure the mental and performance skills in the light of the content and its behavioral objectives. The test has been focused on the substantive rules of the tests based on a multiple choice; as each question consists of introduction and four choices and one of them is the correct answer. Following steps have been followed in preparing the test:

a- Determining the objective of the test.

b- Test building and its piloting exploratory.

c- Adopting the test in its final image.

The following are steps of test building in details:

1) Preparing the measurement test of the mental and performance skills in order to:

a. Using it as pre-test to measure what the students of the eighth grade have previous mental and performance skills around the content, the subject of the study.

b. Using it as port-test to measure the effectiveness of the program after application the experiment.

c. Using the results in verification of the questions of the study. 
The test has been used in recognizing the extent of achieving the objective of the study and effectiveness of the program, by applying the measurement test of the mental and performance skills previously on the sample of the study (The experimental and control group), then applying it consequently after teaching the content using iPad Device in the Experimental Group, meanwhile using the Traditional Teaching Method in the Control Group. By processing the results statistically, the change level in the mental and performance skills can be measured.

2) Test building and its piloting exploratory and including

a. Determining the behavioral objectives for the educational content: The behavioral objectives, specifically formulated for the unit intended to be taught in accordance with the Curriculum of Kuwait and Islamic World for the Intermediate Eighth Grade, have been approved.

b. Determining the Type of the Test: The substantive test has been chosen to suit with the objective of the study. The questions have been formulated in the pattern of choosing the answer among multiple alternatives. The test consists of 20 substantive questions and each item consists of introduction and four choices, and only one is the correct. One grade is calculated for every question.

c. Formulation the Test Vocabulary: When formulating the following test vocabulary, it was taken into account:

- When formulating the introduction of each question, it was taken into account submitting a direct question, its answer will be the four choices which following the question. The number of the questions is 20 substantive questions.

- To measure one of the field levels intended to be measured (Mental and Performance Field). Questions to measure the mental field represented in (11) questions, meanwhile questions to measure the performance fields represented in (9) questions.

- Phrases and graphics are clear and can't afford more than explanation and sufficient information, skills and data which contributes in access to the right solution are available in it.

- Number of answers for each item is four choices.

- To arrange the correct answers are irregular randomly.

d. The Sincerity of the Test:

The measurement test of the mental and performance skills has been presented on a group of arbitrators (members of faculty in the College of Education, instructional Supervisors for Social Studies Subject in order to thier arbitration scientifically and educationally in the following aspects:

1. The clarity of test vocabulary.

2. The validity of the scientific material for the question.

3. Measurement of each question to its specific level.

4. The appropriateness of the test items to measure the educational objectives.

5. The correlation of the test items in the content intended to be measured.

After taking the opinions and directives of the arbitrators, the measurement test of the mental and performance skills has been reformulated in its final image, following the arbitration and its preparation of applying it on explanatory sample.

\section{e. Pilot Experiment for the Test:}

The achievement test has been experimenting on a pilot sample consisted of (22) female students in the intermediate eighth grade. The objective of this application was the calculation of the test stability. Cronbach's Alpha Stability Coefficient has been used to measure the stability of the test. Test Stability Coefficient was (0.702), and it is coefficient could be trusted.

The convergence of the Arithmetic Means between the experimental and control groups is returned to the procedures followed in Al-Shifaa Bint Ouf School around dividing the female students on the classrooms on the basis of diversity in their achievement level.

- Verification of the Equality of the Two Groups:

In order to the equality of the two experimental and control groups, the researcher has carried out pre-test on both groups. The duration of the test has been (40) minutes as scheduled. The table no (3) shows the results of the pre-test: 


\subsection{Experiment Steps}

A group of steps has been followed in applying the usage of IPad Device in the Education in the experimental group represented in:

A. Applying the pre-test on the two experimental and control groups, before starting the experiment.

B. Providing the iPad devices required in the experiment, as iPad devices have been distributed on the students in the experimental group classroom without the control group.

C. A group of applications and programs has been chosen to use it in the experimental group classroom.

D. Equipping the classroom dedicated to apply the experiment with the necessary equipment.

E. Training the experimental group on dealing with the iPad device; as the students have been trained on how to use the educational applications and programs to achieve the learning objectives.

After the completion of the preparations and fittings needed to conduct the experiment, it has been met with the teachers of the school subject for the two experimental and control groups to alert some of the instructions related to the experiment. The application of the study for the two experimental and control groups has started according to the time plan prepared by the teacher of the subject. In a parallel line, the same unit for the control group started to be teaching. The experiment has been conducted for 6 academic weeks by two lessons per week, as the number of lessons reached 12 academic lessons.

The plan followed to apply the teaching of the educational material on iPad Device:

1. Before the academic lesson: The teacher has equipped the classroom by iPad Device and provided the wireless communication service to enable the female students from searching and investigating the required information.

2. The academic lesson which takes (45) minutes starts with distribution iPad Devices on the female students, thus presenting the introductory activity around the subject of the lesson within five minutes of the time of the academic lesson till the female students to recognize the subject of the lesson before starting in learning through the iPad Device.

3. The female students begin to open the Keynote Application which allows presenting the educational software through it. The female students look forward the slides and make the required through the activities presented on the slides with providing the needed supporting after performing the activities. As the educational activities are varied as searching in the World Wide Web and using the useful applications which characterized by ease of its using such as, Google Earth Application and Educational Games. The learning time takes through iPad Device (35) minutes from the total of time of the academic lesson.

4. At the last five minutes of the academic lesson, the teacher carried out a final activity for the female students through the iPad Device as evaluation process for them.

5. Applying the measurement test of the Mental and Performance Skills Consequently:

The test has been carried out consequently for the two experimental and control groups after the completion of the experiment. The test has taken a period of time of (40) minutes as scheduled. The questions have been read on the female students by the researcher to show any inquiry about the test. Then the researcher has corrected all answer papers to get out the final grade for each female student, then separating the questions related to the mental side than the questions related the performance side and calculate the grades for each field in order to entering them in the statistical analysis program to recognize the results of the experiment.

The Statistical Analysis Program (SPSS) has been used:

1- T-test: To illustrate the differences between the performance of the experimental group and control group.

2- Cronbach's Alpha Equation to make sure of the stability of the test.

\section{Results and Discussions}

The following is a presentation of the most important results of the study in order to replying the questions of the study:

First Question: Are there statistically significant differences between the averages of the experimental group and the control group in acquisition of the mental skills in the pre-test? 
Table 1. T-test to the Results of the First Question for the Two Experimental and Control Groups

\begin{tabular}{llllll}
\hline Group & $\mathrm{N}$ & $\begin{array}{l}\text { Arithmetic } \\
\text { Mean }\end{array}$ & $\begin{array}{l}\text { Standard } \\
\text { Deviation }\end{array}$ & T-test & $\begin{array}{l}\text { Significance } \\
\text { Level }\end{array}$ \\
\hline Experimental & 24 & 8.33 & 0.96 & 0.827 & .0413 \\
Control & 24 & 8.11 & 0.84 & & \\
\hline
\end{tabular}

The results set out from the previous table no (1) to answer the first question which is: Are there statistically significant differences between the averages of the experimental group and the control group in acquisition of the mental skills in the pre-test?, showed that there are no statistically significant differences between the averages of the experimental group and the control group in acquisition of the mental skills in the pre-test. As the averages of the experimental group came as (8.33) but for the control group as (8.11), as it has been done during the using of T-test to compare between averages and it appeared that there are no differences which means that both groups have the same level of the mental skills before applying the experiment. This may return to that both groups are in the eighth grade level and the existence of the both groups in the same school led to the similar conditions surrounding the learning process for the two groups. As (Borham, 2005) points to that the learning process is affected by the environment which the student exists in as the factors of the environment which affecting in learning are divided into the physical aspects which surrounding the student and moral aspects which means the relationships of the learners with the teacher and their relationship among themselves. As far as these factors are positive and successful in the classroom, it leads to achieve the better learning. Making sure of the similar conditions surrounding the sample of the study is very important to maintain the integrity of the experiment.

Second Question: Are there statistically significant differences between the averages of the experimental group and the control group in acquisition of the performance skills in the pre-test?

Table 2. Shows the Results of T-test for the Results of the Second Question for the Two Experimental and Control Groups

\begin{tabular}{llllll}
\hline Group & $\mathrm{N}$ & $\begin{array}{l}\text { Arithmetic } \\
\text { Mean }\end{array}$ & $\begin{array}{l}\text { Standard } \\
\text { Deviation }\end{array}$ & T-test & $\begin{array}{l}\text { Significance } \\
\text { Level }\end{array}$ \\
\hline Experimental & 24 & 8.05 & 0.152 & 0.624 & 0.535 \\
Control & 24 & 8.33 & 0.155 & & \\
\hline
\end{tabular}

The results set out in the previous table no (2) showed that there are no statistically significant differences between the averages of the two experimental and the control groups in the performance skills in the pre-test, which means the equality of the two groups in the level of performance skills before applying the using of iPad Device in the Education. This returns to their existence in the same educational level, as the performance skills are similar in the Social Studies Subject and represented in the skills of determination on the map, reading and drawing it and the skill of draw the charts and graphs.

Third Question: Are there statistically significant differences between the averages of the experimental group and the control group in the mental skills of the students in the post-test?

Table 3. T-test shows the Results of the Third Question for the Two Experimental and Control Groups

\begin{tabular}{llllll}
\hline Group & $\mathrm{N}$ & $\begin{array}{l}\text { Arithmetic } \\
\text { Mean }\end{array}$ & $\begin{array}{l}\text { Standard } \\
\text { Deviation }\end{array}$ & T-test & $\begin{array}{l}\text { Significance } \\
\text { Level }\end{array}$ \\
\hline Experimental & 24 & 12.625 & 1.345 & 3.313 & .002 \\
Control & 24 & 11.166 & 1.685 & & \\
\hline
\end{tabular}

The results set out in the previous table no (3) showed that there are statistically significant differences at the significance level (0.05) between the two experimental and the control groups in the mental skills in the post-test. The results were for the experimental group. T-test has been used to compare between the averages of the grades of two groups. As the averages of the grades of the experimental group came as (12.625); meanwhile the averages of 
the grades of the control group came as (11.166). The significance level showed the existence of these differences. The researchers attributed this result to:

1. The nature of the applications included for explanation and simplifying the scientific material using iPad Device in addition to the activities which provoke the thinking of the learners and adding the excitement and interesting element for the learning process.

2. The content of the program which uses the educational drawings, images and movies which help to embody the concepts including the images and this gives greater educational impact than given by the written words which helps on the learning survival.

This result is consistent with the results of the previous studies which dealt with the impact of using the educational technology in the education. This is consistent with the (Mango, 2015) Study which confirmed on the effectiveness of the iPad Device in enhancing the active learning for students and achieving the effective participation within the classroom.

In addition to the study of each of (Al-tweley, 2011) and (Al-swat, 2011), which specialized in searching for the effectiveness of the educational technology in general in acquiring the mental skills in Bloom's Taxonomy in the social studies which proved its effectiveness in development the academic achievement and learning retention.

Unlike the using of the method of the traditional cooperative learning in the control group, as the teaching methods free of the educational technology are inappropriate in our current era and limit the learning process for the students as it lacks to the interesting element which introduce the boredom in the educational process.

Fourth Question: Are there statistically significant differences between the averages of the experimental group and the control group in the performance skills of the students in the post-test?

Table 4 T-test shows the results of the Fourth Question for the Two Experimental and Control Groups

\begin{tabular}{llllll}
\hline Group & $\mathrm{N}$ & $\begin{array}{l}\text { Arithmetic } \\
\text { Mean }\end{array}$ & $\begin{array}{l}\text { Standard } \\
\text { Deviation }\end{array}$ & T-test & $\begin{array}{l}\text { Significance } \\
\text { Level }\end{array}$ \\
\hline Experimental & 24 & 5.75 & .532 & 2.967 & .005 \\
Control & 24 & 5.04 & 1.042 & & \\
\hline
\end{tabular}

The results set out in the previous table no (4) shows that there are statistically significant differences at the significance level (0.05) between the two experimental and the control groups in the performance skills in the post-test for the experimental group. (T) Test has been used to compare between the averages of the grades of two groups. As the averages of the grades of the experimental group came as (5.75); meanwhile the averages of the grades of the control group came as (5.04). This may return to the effectiveness of using the iPad Device as one of the means of the Educational Technology in acquisition the performance skills especially in Social Studies Subject. These skills are represented in the skill of drawing the map; the skill of reading the map; the skill of determining the map; the skill of drawing the charts and analyzing it and the skill of the graphs. Each of (Kresenti\&Fievez, 2013) has pointed to that using iPad Device within the classroom develops the skills of the students and encourages them on learning and positive interaction. The impact of using the technology in acquisition the performance skills in (Abu-Hamada, 2013) Study which showed the effectiveness of using one of the means of the educational technology represented in smart board, the skills of using the maps and the acquisition of the geographical concepts. (Jones, 2007) has demonstrated the effectiveness of iPad Device in encouragement the discussion and cooperation between the students in addition to its positive impact on the educational process as whole.

\section{Discussion}

iPad Device is one of the modern techniques internationally deployed, and considers one of the mobile learning forms. Whereas (Irelan\&Woollerton, 2010) identifies it as tablet computer device including touch screen to allow users to control the device using fingers. Al-Rwaily (2014) adds that the iPad Device is working ,by IOS System and running several types of multimedia such as newspapers, magazines, digital books, video, music, games and all iPhone Programs. In 2010, iPad Device appeared as invocations of era which stunned the world, so its usage has been activated 
in several fields, as (Huber 2012) points that the device was designed to be a source of the books and movies and operator for applications, music and Internet. (Irelan\& Woollerton, 2010) has mentioned that the iPad Device has a role in providing some of the facilities in the educational process, as students can be able to choose the audible and visual materials to commensurate their needs, uploading and sharing information with others, using it as a device to present the information and presentations due to its containing easy to use.

Our studies report that training the experimental group on dealing with the iPad device; as the students have been trained on how to use the educational applications and programs to achieve the learning. The teacher on the other hand has equipped the classroom by iPad Device and provided the wireless communication service to enable the students from searching and investigating the required information in social studies.

However, the results indicate that the significant differences in the performance skills, with the experimental group performing very highly better than the control group. These differences were found to be significant. At the same time, significant differences are found across the two groups for the mental performance, with the experimental group revealing the greatest gains. These results suggest that potentially, the use of iPads had a significant positive impact on the experimental group student's learning of these higher-order skills, for the effectiveness of using the iPad in learning to acquire the mental and performance skills of eighth grade students in social studies in Kuwait.

\section{Conclusion}

iPads and digital devices have been securing their place in educational institutions and is clear that these devices have not only become part of our daily lives but are likely to stay with us and in our schools for a long time. This research, the Effectiveness of using the iPad in learning to acquire the mental and performance skills in teaching the social studies, is intended to investigate the effectiveness on students iPad use. It aimed to better understand the iPad use for educational purposes from the perspective of the student's .It recognizes that more students are increasingly to digital and mobile technologies as members of a digital generation. Teacher use the ipad to meet the specific learning needs of students and support engaging, interesting collaborative learning, and students used the iPad to take a great control of their learning.

This experimental design study present the Effectiveness of using the iPad in learning to acquire the mental and performance skills in teaching the social studies at Kuwait showed that technology has a significant role to play in enhancing the delivery of social studies as teaching and learning in the primary sector.

The findings highlight that the iPad is appealing and can support students' developing literacy, communicative and participatory learning skills and understandings. It shows the effectiveness of using the iPad Device in acquisition the performance skills in social studies such as drawing, reading and determining maps, drawing and analyzing charts and graphs. Finally, findings indicated that students not only enjoyed using the iPads but also we believed that the iPads helped them learn.

In conclusion, in spite of potential limitations, results of the study suggest that the scientific material using iPad Device in addition to the activities which provoke the thinking of the learners and adding the excitement and interesting element for the learning process. The findings from this study points to that the learning process is affected by the environment which the student exists in as the factors of the environment which affecting in learning are divided into the physical aspects which surrounding the student and moral aspects which means the relationships of the learners with the teacher and their relationship among themselves, as far as these factors are positive and successful in the classroom, it leads to achieve the better learning, making sure of the similar conditions surrounding the sample of the study is very important to maintain the integrity of the experiment.

This study suggested that future research should consider the awareness of the officials in the Ministry of Education, to the importance of applying the usage of iPad Device, in the teaching process in all educational phases. Awareness of the teachers of the social studies to the necessity of activation, the iPad Device in the Academic Lesson through conducting training courses and workshops for the teachers around how to apply the using of iPad Device in the teaching, and Designing applications and software on iPad Device to teach the social studies according to the quality and efficiency standards in collaboration with the Promotion and Development Centers.

\section{References}

Abdelbaset (2005). The successful applications and methods of using the technology information and telecommunication in educating and learning the geography. The associate of Technology and Humanitarian Development: Education Journal on Internet, A5, 47-59. 
Abdell Aty, Mohammad AL-Bataa. (2015). Using the Web Technology in education. The Library of EducationUniversity of Alexandria.

Abu Hamada, Soha. (2013). The impact of using the smart board in teaching the subject on the development of the geography concepts and the skill of using maps for 9th grade in Gaza Governorate. (Master's Thesis) Al-Azhar University, Gaza.

Al-Hamamy, Mohammad. (2006). M-Learning is a new stage of the E-Learning. Informative Magazine, 6.

Al-Hela, Mohammad Mahmoud. (2003). Learning Technology between Theory and Application. Oman: Dar Al-Maissara.

Al-Kebiesy, Abdelwahed Hamied \& Farhan, Mohammad Sami. (2012). Reflections of the modern education's techniques on the educational process. Babel: University of Anbar.

Al-Nabhani, Saud Bin Suliman. (2003). The effectiveness of using the strategy of co-learning in development some skills of map comprehension for the 4th grade students (Master's Thesis). Sultan Qaboos University, Sultanate of Oman.

AL-Omari, Omar Hussein. (2012). The effectiveness of a computerized educational program in development of the cognitive thinking for the 7th grade students in Jordan. University of Damascus, 28(1), 265-300.

Al-Qulla, FakhrEldien\& Siyam, Mohammad (2011). Techniques of Education. Damascus: University of Damascus.

Ashtiwa, Fawzi \& Elian, Ribhi. (2010). Technology of Education (Theory \& Application). Oman: Dar Safa for Publication and Distribution.

Al-Rwaily, Ramadan Morjji. (2014). The effectiveness of using Tablet BC and its educational applications in developing the students of 4th grade in Mathematics. Master's Thesis. King Abdul-Aziz University. KSA.

AL-Sawat, Fahad Haliel. (2011). The effect of using the computer in maintaining the learning level of the 4th grade in geography in accordance with the 1st three levels of Bloom category (Comprehension, Understanding, Application). Comprehension according to the traditional method. Umm Al-Qura University Journal of Education and Psychology Sciences, 15(2).

Al-Tweley, Merfat Abdelrahman Saleh (2011). The impact of the cognitive trips across Web (Web Quest) in teaching the social studies on the academic achievement and the development of technical progress for high school students (girls). Master's Thesis, Umm Al- Qura University, KSA.

Barhem, NidalAbdellatif. (2006). Methods of teaching the social studies. Oman, Library of Arab Society.

Chau, C., Block, L., \& Jesness, R. (2014). Strategies and challenges in iPad initiative. Tenth international conference mobile learning. University of St. Thomas Minneapolis, USA, 133- 140.

Culen, A., \& Casparini, A. (2011). I pad: A New Classroom Technology? A report From Two Pilot Studies. Information Science and e-society, Norway, 199-20.

Du'mus, Mustafa Nimr. (2011). Technology of learning and Computerizing the education. Oman: Dar Ghaidaa.

Eyal, L. (2015). Taxonomy of Students' Use of the I pad in education: A Pilot Interdisciplinary. Journal of e-skills and Life Long Learning, Levinsky College of education, Isreal, 11, 67-84.

Farisi, M. (2016). Developing the 21th century social studies skills through technology integration. Turkish online journal of Distance Education, 17(1), 16-30.

Huber, S. (2012). I pad in The Classroom. Books on Demand GmbH, Norderstedt.

Ireland, G., \& Woollerton, M (2010). The Impact of the iPad and iPhone on Education. Journal of Bunkyo Gakuin University Department of Foreign Languages \& Bunkyo Gakuin College, 2011.

Jones, Jeela. (2007). Connected Learning in Co-operative education. International Journal of Teaching and Learning in Higher education, 19(3), 263-273.

Karsenti, T., \& Fievez, A. (2013). The I pad in education: uses, benefits. and challenges. Library and Archives Canada.

Mahdi, Hassan Ribhi. (2015). Technology of Learning and Education. Oman: Dar Almaisra for publication and distribution.

Mango, O. (2015). I pad Use and Student Engagement in the Classroom. The Turkish Online Journal of Educational 
Technology, 14(1), 53-57.

Qurrashi, Abdelghafar, Badowd, Ashraf, Abdelal, Ahmad. Abdelatti, Hassan \& Al-Hafnawi, Mahmoud. (2015). The reality of the experience of Taif University in employment the applications of Mobile and Tablet appliances in the composed e-learning through using the management system of learning Blackboard from the point of view of students. The 1st International Conference of Education Faculty, Al-Baha University "Education ... Future Horizone" from 12 to 15 April, King Abdulaziz Center for World Culture, KSA.

Rossing, J., Miller, M., Cecil, A., \& Stamper, S. (2012). I Learning; The future of higher education Students perception on learning with mobile tablets. Journal of the scholarship of teaching and learning, 12(2), 1-26.

Saleem, Taiseer \& Rawas (2012). Techmnology of M-learning (Theoretical Study). Al- Balqa' Applied University (BAU), 24, 191-216.

Shepard, I., \& Reeves, B. (2011). Ipad or ifad- the reality of a paperless classroom. Abilene Christian UniversityMobility Conference, 1-24. 